\title{
Evidence of Concomitantly Increasing Stroke and Dementia Prevalence among those 80 Years and Older in Ontario, Canada, 2003-04 to 2012-13
}

\author{
Joshua O. Cerasuolo, Mahmoud Reza Azarpazhooh, Moira K. Kapral, \\ Lauren E. Cipriano, Vladimir Hachinski
}

ABSTRACT: Among those aged 80 years and older in Ontario, Canada, stroke and dementia incidence declined concomitantly from 200203 to 2013-14. This study aimed to report the concurrent temporal trends of stroke and dementia prevalence in Ontario among the same age demographic. The prevalence of both stroke and dementia increased from 2003-04 to 2012-13 in both sexes and the magnitude in which prevalence of dementia increased over time exceeded that of stroke. The substantial increase in the prevalence of dementia may be because of increased recognition and diagnoses of dementia and increased survival of stroke patients who are at higher risk of developing dementia.

RÉSUMÉ: Des preuves quant à une augmentation simultanée de la prévalence des AVC et de la démence. De 2002-2003 à 2013-2014, on a noté une diminution simultanée de l'incidence des AVC et de la démence parmi les individus âgés de plus de 80 ans vivant en Ontario (Canada). Ce qui nous intéresse dans cette étude, ce sont les tendances temporelles simultanées en ce qui a trait à la prévalence des AVC et de la démence au sein de la même tranche d'âge et dans la même province. On a ainsi noté que tant la prévalence des AVC que celle de la démence ont augmenté entre 2003-2004 et 2012-2013, et ce, tant chez les hommes que chez les femmes. Cela dit, l'ampleur de l'augmentation de la prévalence de la démence a fini par dépasser au fil du temps celle des AVC. Il se pourrait que l'augmentation substantielle de la prévalence des cas de démence puisse être attribuée à un dépistage accru et à l'établissement de plus nombreux diagnostics ainsi qu'à un accroissement de la survie des patients victimes d'AVC, ces derniers étant alors plus susceptibles d'être atteints de démence.

Keywords: Stroke, Aging, Dementia

doi:10.1017/cjn.2018.347

Can J Neurol Sci. 2019; 46: 105-107

Stroke and dementia pose a significant threat to global public health. In addition to sharing common cardiovascular risk factors, ${ }^{1,2}$ stroke has been shown to approximately double the risk of subsequent incident dementia. ${ }^{3}$ As stroke and dementia becomes more frequent with the aging population, widespread prevention initiatives are essential to combat the health and economic burden imposed by both cerebrovascular conditions.

We recently demonstrated a concomitant decline in stroke and dementia incidence in Ontario, Canada from 2002 to 2013 among those aged 80 years and older. ${ }^{4}$ This may be attributable to improved primary prevention targeting shared risk of factors of stroke and dementia, and to a decreased incidence of dementia directly related to the decreased incidence of stroke. ${ }^{4}$ Independent of changes in stroke incidence, improvements in acute stroke care and rehabilitation may also have contributed to a decline in the incidence of dementia. In order to further understand the relationship of stroke and dementia in the Ontario's eldest population, this study examines temporal trends in the prevalence of stroke and dementia in those aged 80 years and older from 2003-04 to 2012-13.

We obtained data on the prevalence of stroke and dementia in Ontario through a publicly available online data portal managed by the Public Health Agency of Canada. ${ }^{5}$ The Canadian Chronic Disease Surveillance System (CCDSS) monitors descriptive metrics of various health conditions using administrative health databases (e.g., health registries, hospital discharges, physician billing claims, and prescription dispenses). ${ }^{6}$ The accuracy of the validated diagnostic algorithms which identified cases for stroke and dementia are described elsewhere. ${ }^{7,8}$ Prevalence was defined as all prevalent cases in a particular year of observation, divided by the total population with valid Ontario health insurance. ${ }^{5} \mathrm{We}$

\footnotetext{
From the Department of Clinical Neurological Sciences, London Health Sciences Centre, Western University, London, Ontario, Canada (JOC, MRA, VH); Department of Epidemiology and Biostatistics, Schulich School of Medicine and Dentistry, Western University, London, Ontario, Canada (JOC, MRA, LEC, VH); Department of Neurology, Ghaem Hospital, Mashhad University of Medical Sciences, Mashhad, Iran (MRA); Institute for Clinical Evaluative Sciences, Toronto, Ontario, Canada (MKK); Department of Medicine, University of Toronto, Toronto, Ontario, Canada (MKK); Ivey Business School, Western University, London, Ontario, Canada (LEC).

Received April 11, 2018. Final Revisions Submitted August 10, 2018. Date of AcCeptance August 19, 2018.

Correspondence to: Vladimir Hachinski, Department of Clinical Neurological Sciences, London Health Sciences Centre, University Hospital, 339 Windermere Road, London, ON, Canada N6A 5A5. Email: vladimir.hachinski@lhsc.on.ca
} 
Table 1: Crude prevalence rates (per 1,000 population) of stroke and dementia among those aged 80 years and older, fiscal years from 2003-04 to $2012-13^{5}$

\begin{tabular}{|c|c|c|c|c|c|c|c|c|c|c|}
\hline \multirow{2}{*}{$\begin{array}{l}\text { Stroke } \\
\text { Fiscal year }\end{array}$} & \multicolumn{5}{|c|}{ Women } & \multicolumn{5}{|c|}{ Men } \\
\hline & $\begin{array}{l}\text { Total } \\
\text { cases }\end{array}$ & Population & $\begin{array}{l}\text { Crude prevalence } \\
\text { rate }\end{array}$ & LCL & UCL & $\begin{array}{l}\text { Total } \\
\text { cases }\end{array}$ & Population & $\begin{array}{l}\text { Crude prevalence } \\
\text { rate }\end{array}$ & LCL & UCL \\
\hline 2003 & 48,930 & 299,440 & 163.4 & 162.0 & 164.9 & 30,720 & 168,600 & 182.2 & 180.2 & 184.3 \\
\hline 2004 & 52,060 & 313,130 & 166.3 & 164.8 & 167.7 & 32,950 & 178,070 & 185.0 & 183.0 & 187.0 \\
\hline 2005 & 55,030 & 326,470 & 168.6 & 167.2 & 170.0 & 35,260 & 188,380 & 187.2 & 185.2 & 189.1 \\
\hline 2006 & 57,690 & 339,040 & 170.2 & 168.8 & 171.6 & 37,530 & 199,140 & 188.5 & 186.6 & 190.4 \\
\hline 2007 & 59,760 & 351,340 & 170.1 & 168.7 & 171.5 & 39,480 & 209,760 & 188.2 & 186.4 & 190.1 \\
\hline 2008 & 61,500 & 355,840 & 172.8 & 171.5 & 174.2 & 41,400 & 215,660 & 192.0 & 190.1 & 193.8 \\
\hline 2009 & 63,390 & 365,840 & 173.3 & 171.9 & 174.6 & 43,250 & 225,230 & 192.0 & 190.2 & 193.8 \\
\hline 2010 & 65,290 & 377,370 & 173.0 & 171.7 & 174.3 & 45,210 & 236,580 & 191.1 & 189.3 & 192.9 \\
\hline 2011 & 66,840 & 387,320 & 172.6 & 171.3 & 173.9 & 46,990 & 246,600 & 190.6 & 188.8 & 192.3 \\
\hline 2012 & 68,250 & 397,280 & 171.8 & 170.5 & 173.1 & 48,800 & 257,180 & 189.8 & 188.1 & 191.4 \\
\hline Absolute rate change & & & 8.4 & & & & & 7.6 & & \\
\hline Relative rate change, $\%$ & & & 5.1 & & & & & 4.2 & & \\
\hline $\begin{array}{l}\text { Kendall } \tau \text {-b correlation } \\
\text { coefficient }\end{array}$ & & & 0.600 & & & & & 0.539 & & \\
\hline$p$-value for trend & & & 0.020 & & & & & 0.039 & & \\
\hline Dementia & \multicolumn{5}{|c|}{ Women } & \multicolumn{5}{|c|}{ Men } \\
\hline Fiscal year & $\begin{array}{l}\text { Total } \\
\text { cases }\end{array}$ & Population & $\begin{array}{l}\text { Crude prevalence } \\
\text { rate }\end{array}$ & LCL & UCL & $\begin{array}{l}\text { Total } \\
\text { cases }\end{array}$ & Population & $\begin{array}{l}\text { Crude prevalence } \\
\text { rate }\end{array}$ & LCL & UCL \\
\hline 2003 & 53,430 & 299,440 & 178.4 & 176.9 & 180.0 & 21,940 & 168,600 & 130.1 & 128.4 & 131.9 \\
\hline 2004 & 57,950 & 313,070 & 185.1 & 183.6 & 186.6 & 24,290 & 178,030 & 136.4 & 134.7 & 138.2 \\
\hline 2005 & 61,910 & 326,280 & 189.7 & 188.3 & 191.2 & 26,380 & 188,280 & 140.1 & 138.4 & 141.8 \\
\hline 2006 & 65,840 & 338,770 & 194.4 & 192.9 & 195.8 & 28,740 & 198,990 & 144.4 & 142.8 & 146.1 \\
\hline 2007 & 69,110 & 351,030 & 196.9 & 195.4 & 198.4 & 30,660 & 209,590 & 146.3 & 144.7 & 147.9 \\
\hline 2008 & 72,740 & 355,470 & 204.6 & 203.1 & 206.1 & 32,830 & 215,450 & 152.4 & 150.7 & 154.0 \\
\hline 2009 & 76,240 & 365,450 & 208.6 & 207.1 & 210.1 & 34,850 & 225,000 & 154.9 & 153.3 & 156.5 \\
\hline 2010 & 79,680 & 376,970 & 211.4 & 209.9 & 212.8 & 37,160 & 236,310 & 157.3 & 155.7 & 158.9 \\
\hline 2011 & 82,620 & 386,900 & 213.5 & 212.1 & 215.0 & 39,340 & 246,280 & 159.7 & 158.2 & 161.3 \\
\hline 2012 & 85,700 & 396,860 & 215.9 & 214.5 & 217.4 & 41,430 & 256,800 & 161.3 & 159.8 & 162.9 \\
\hline Absolute rate change & & & 37.5 & & & & & 31.2 & & \\
\hline Relative rate change, $\%$ & & & 21.0 & & & & & 24.0 & & \\
\hline $\begin{array}{l}\text { Kendall } \tau \text {-b correlation } \\
\text { coefficient }\end{array}$ & & & 1.000 & & & & & 1.000 & & \\
\hline$p$-value for trend & & & $<0.001$ & & & & & $<0.001$ & & \\
\hline
\end{tabular}

Crude prevalence rate per 1,000 population. Years are expressed fiscally - year 2003 denotes April 1, 2003 to March 31, 2004. LCL=lower 95\% confidence limit; UCL $=$ upper $95 \%$ confidence limit.

reported crude stroke and dementia prevalence trends from fiscal years 2003-04 to 2012-13 in those aged at least 80 years, stratified by sex. Age-standardization was not completed owing to unavailability of more granular age strata. Crude rates were accompanied by $95 \%$ confidence intervals; significant trends were identified using the Kendall $\tau$-b correlation coefficient. Analysis was completed using STATA 13.

From fiscal years 2003-04 to 2012-13 (Table 1), crude stroke prevalence increased $5.1 \%$ (163.4-171.8 per 1000 population, $p=0.020)$ in women and $4.2 \%(182.2-189.8$ per $1000, p=0.039)$ in men. Similarly, with a higher magnitude across the same timeframe, crude dementia prevalence increased by $21.0 \%$ (178.4-215.9 per $1000, p<0.001)$ in women and $24.0 \%$ (130.1161.3 per $1000, p<0.001)$ in men. In each year from $2003-04$ to 2012-13 (Figure 1), dementia prevalence was higher among women, whereas stroke prevalence was higher among men.

We found that the prevalence of both stroke and dementia increased between 2003-04 and 2012-13 in Ontario, Canada, and the magnitude of the increase in dementia prevalence was far greater than that of stroke. This was consistent with a worldwide study of dementia burden among 21 Global Burden of Disease regions that projected prevalence to approximately double every 


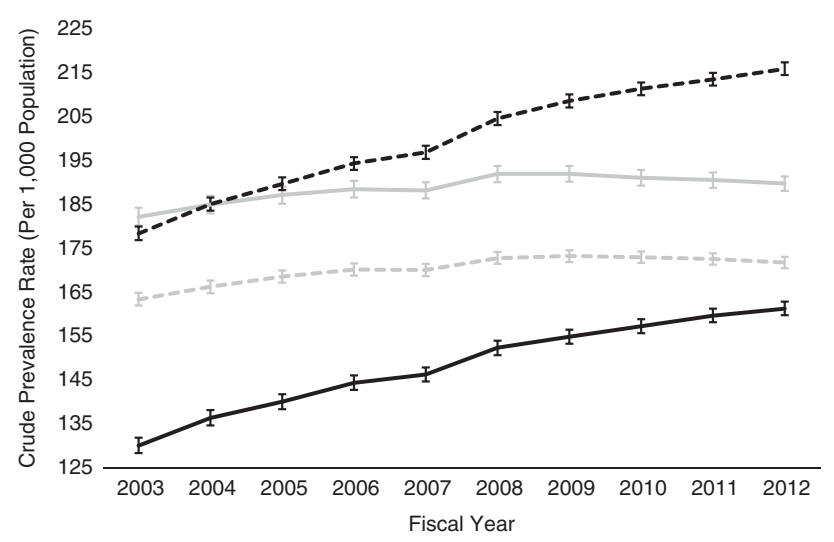

Figure 1: Temporal trends of crude stroke and dementia prevalence rates (per 1000 population) among those aged 80 years and older, fiscal years from 2003-04 to 2012-13. ${ }^{5}$ Black lines represent dementia, and gray lines stroke. Dashed lines symbolize women, and solid lines men. Error bars represent 95\% confidence intervals around point estimates. Refer to Table 1 for corresponding metrics.

20 years. $^{9}$ Since the rate of increase in dementia prevalence greatly exceeds that of stroke, the increase in dementia prevalence cannot be fully explained by cerebrovascular mechanisms such as a prior stroke. ${ }^{10,11}$ In addition, our observations may be a consequence of more patients suffering milder strokes but remain undiagnosed, and therefore the temporal trends of stroke prevalence are biased downward. Given the documented decline in stroke incidence, ${ }^{4}$ the steady increase in dementia prevalence suggests that people with dementia may be living longer with the disease or being diagnosed at a younger age.

The previously observed temporal decrease in stroke and dementia incidence ${ }^{4}$ may be in part because of primary prevention efforts of Ontario's integrated stroke system-preventive measures are successfully targeting risk factors common to both stroke and dementia, ${ }^{1,2}$ and the risk of dementia is further reduced by decreasing the incidence of stroke since stroke is known to double the risk of dementia. ${ }^{3}$ Yet, it is possible that a decrease in the incidence of stroke and/or dementia are caused by older individuals dying from other health conditions (i.e., heart failure, cancer, respiratory illness, etc.), potentially precluding a diagnosis of stroke and/or dementia. The current study serves to counter that hypothesis and instead suggests that the average life expectancy after stroke and/or dementia diagnosis is increasing. This may be because of improvements in acute stroke care, rehabilitation, and secondary prevention and treatment of comorbid conditions. However, since our analysis was based on crude metrics, the increase in prevalence is partly a consequence of Canada's aging population.

Our study has limitations. Since more granular age strata among the elderly were not available, we did not report agestandardized metrics. Second, we used administrative data to identify cases, and may have underestimated prevalent dementia and stroke. ${ }^{12}$ In addition, given the unavailability of individuallevel data, the analytical scope was limited. We also did not provide information on the underlying reasons for the observed trends, pending further, more elaborate investigation using individual-level data sources.

This study provides novel information on the concurrent temporal trends of stroke and dementia prevalence in Ontario, Canada. Given the substantial increases in dementia prevalence in women and men from 2003-04 to 2012-13, we speculate that improved stroke prevention, acute stroke care, and rehabilitation may have prolonged survival following a diagnosis of stroke or dementia. More importantly, we provide evidence for the increasing burden of stroke and dementia in Ontario, Canada, like other high-income countries, and must prepare for this impending public health concern with the potential for high consumption of health system resources. Future research should evaluate the clinical benefit of stroke-related health system investments on subsequent cognition.

\section{ACKNOWLEDGMENTS}

The authors thank Catherine Pelletier and Cynthia Robitaille (Public Health Agency of Canada) for their assistance with navigating the Canadian Chronic Disease Surveillance System (CCDSS), and their insightful comments on this manuscript.

\section{Statement of Authorship}

JOC and VH conceived the study idea. JOC drafted all manuscript versions and conducted the statistical analyses. LEC and $\mathrm{VH}$ supervised the study. JOC, MRA, MKK, LEC, and VH interpreted results, critically reviewed the manuscript for important intellectual content, and approved final version of this manuscript.

\section{Disclosures}

JC, MRA, MK, LC, and VH have nothing to disclose.

\section{REFERENCES}

1. Sahathevan R, Brodtmann A, Donnan GA. Dementia, stroke, and vascular risk factors: a review. Int J Stroke. 2012;7(1):61-73.

2. Gardener H, Wright CB, Rundek T, Sacco RL. Brain health and shared risk factors for dementia and stroke. Nat Rev Neurol. 2015;11(11):651-7.

3. Savva GM, Stephan BC, Alzheimer's Society Vascular Dementia Systematic Review G. Epidemiological studies of the effect of stroke on incident dementia: a systematic review. Stroke. 2010;41(1):e41-6.

4. Cerasuolo JO, Cipriano LE, Sposato LA, et al. Population-based stroke and dementia incidence trends: age and sex variations. Alzheimers Dement. 2017;13(10):1081-8.

5. Public Health Agency of Canada. Public Health Infobase. 2017 [cited August 2, 2017]; Available at: http://infobase.phac-aspc.gc.ca/ CCDSS-SCSMC/data-tool/.

6. Feely A, Lix LM, Reimer K. Estimating multimorbidity prevalence with the Canadian Chronic Disease Surveillance System. Health Promot Chronic Dis Prev Can. 2017;37(7):215-22.

7. Jaakkimainen RL, Bronskill SE, Tierney MC, et al. Identification of physician-diagnosed Alzheimer's disease and related dementias in population-based administrative data: a validation study using family physicians' electronic medical records. J Alzheimers Dis. 2016;54(1):337-49.

8. Hall R, Mondor L, Porter J, Fang J, Kapral MK. Accuracy of administrative data for the coding of acute stroke and TIAs. Can J Neurol Sci. 2016;43(6):765-73.

9. Prince M, Bryce R, Albanese E, Wimo A, Ribeiro W, Ferri CP. The global prevalence of dementia: a systematic review and metaanalysis. Alzheimer's Dement. 2013;9(1):63-75.e2.

10. Hugo J, Ganguli M. Dementia and cognitive impairment: epidemiology, diagnosis, and treatment. Clin Geriatr Med. 2014;30 (3):421-42.

11. Raz L, Knoefel J, Bhaskar K. The neuropathology and cerebrovascular mechanisms of dementia. J Cereb Blood Flow Metab. 2016;36(1):172-86.

12. Lopez OL, McDade E, Riverol M, Becker JT. Evolution of the diagnostic criteria for degenerative and cognitive disorders. Curr Opin Neurol. 2011;24(6):532-41. 